Научная статья

УДК 316.6:340.114.5-053.6

DOI: $10.17213 / 2075-2067-2021-5-27-34$

\title{
ДОВЕРИЕ В ПРАВОВОМ СОЗНАНИИ РОССИЙСКОЙ МОЛОДЕЖИ
}

\author{
Яна Юрьевна Искендерова ${ }^{1 凶}$, Ирина Андреевна Левченко \\ Татьяна Леонидовна Сережникова
}

\author{
${ }^{1,2,3}$ Южно-Российский государственный политехнический университет (НПИ) \\ имени М. И. Платова, Новочеркасск, Россия \\ 'yaiskenderova@yandex.ru ${ }^{\bowtie}$ ORСID: 0000-0001-7179-8038, AuthorID РИНЦ: 733591 \\ ${ }^{2}$ Kirka_13.87@mail.ru, ORCID:0000-0002-1900-1455, AuthorID РИНЦ: 838533 \\ ${ }^{3} J u r i s p r u d e n c e-u r g t u @ y a n d e x . r u$, ORCID: 0000-0003-3783-3615, AuthorID РИНЦ: 697382
}

Аннотация. Целью исследования является анализ доверия в правовом сознании российской молодежи как категории «реализации взаимных ожиданий и обязательств» в контексте функиионирования институтов права в российском обществе.

Методологическую базу исследования представляют определенные концептуальные схемы и идеи, выдвинутые видным сочиологом П. Штомпка, считающим, что культура доверия является социальным капиталом, символическое измерение которого конвертируется в экономический, властный, культурный капиталь. Также исследование базируется на идеях современных российских исследователей М. К. Горшкова и Ф. Э. Шереги, которые на уровне масштабного долгосрочного мониторинга молодежи сделали вывод о том, что формирование правового сознания российской молодежи связано не столько с провозглашением идеи построения демократического правового государства, сколько с тем, чтобь молодежь ощущуала, воспринимала и оченивала действующую систему права и реформирования правовых институтов.

Результаты исследования. На основе результатов эмпирических исследований делается вывод о том, что доверие в правовом сознании российской молодежи как интегрированности идей, представлений о праве и его статусе в российском обществе отражает позищию молодежи относительно полуправового характера российского государства и необходимости правового реформирования с иелью возвышения доверия на системный уровень, связанный с укреплением нормативно-правового поля и устранения барьеров на пути модернизации правовой системьл.

Перспективу исследования составляет дальнейший анализ доверия в правовом сознании российской молодежи.

Ключевые слова: доверие, правовое сознание российской молодежи, функционирование институтов права, нормативизм, инструментализм

Для цитирования: Искендерова Я.Ю., Левченко И.А., Сережникова Т.Л. Доверие в правовом сознании российской молодежи // Вестник Южно-Российского государственного технического университета. Серия: Социально-экономические науки. 2021. T. 14, №5. C. 27-34. http://dx.doi.org/10.17213/2075-2067-2021-5-27-34.

(с) Искендерова Я.Ю., Левченко И.А., Сережникова Т. Л., 2021 
Original article

\title{
TRUST IN THE LEGAL CONSCIOUSNESS OF RUSSIAN YOUTH
}

\author{
Yana Yu. Iskenderova ${ }^{\boxplus}$, Irina A. Levchenko ${ }^{2}$, Tatyana L. Serezhnikova ${ }^{3}$ \\ ${ }^{1,2,3}$ Platov South Russian State Polytechnic University (NPI), Novocherkassk, Russia \\ 'yaiskenderova@yandex.ru ${ }^{\bowtie}$,ORCID:0000-0001-7179-8038, AuthorID RSCI: 733591 \\ ${ }^{2}$ Kirka_13.87@mail.ru,ORCID:0000-0002-1900-1455, AuthorID RSCI: 838533 \\ 3Jurisprudence-urgtu@yandex.ru, ORCID: 0000-0003-3783-3615, AuthorID RSCI: 697382
}

\begin{abstract}
The purpose of the study is to analyze trust in the legal consciousness of Russian youth as a category of "realization of mutual expectations and obligations» in the context of the functioning of legal institutions in Russian society.

The methodological basis of the research is represented by certain conceptual schemes and ideas put forward by the prominent sociologist P. Shtompka, who believed that the culture of trust is a social capital, the symbolic dimension of which is converted into economic, power, cultural capitals. The study is also based on the ideas of modern Russian researchers M. K. Gorshkov and F. E. Sheregi, who, at the level of large-scale long-term monitoring of young people, concluded that the formation of the legal consciousness of Russian youth is connected not so much with the proclamation of the idea of building a democratic rule of law, but rather with the fact that young people feel, perceive and evaluate the current system of law and the reform of legal institutions.

The results of the study. Based on the results of empirical research, it is concluded that trust in the legal consciousness of Russian youth, as an integration of ideas, ideas about law and its status in Russian society, reflects the position of young people regarding the semi-governmental nature of the Russian state and the need for legal reform in order to raise trust to a systemic level associated with strengthening the regulatory framework and removing barriers to the modernization of the legal system.
\end{abstract}

The prospect of the study is a further analysis of trust in the legal consciousness of Russian youth.

Keywords: trust, legal consciousness of Russian youth, functioning of legal institutions, normativism, instrumentalism

For citation: Iskenderova Y. Yu., Levchenko I.A., Serezhnikova T.L. Trust in the legal consciousness of Russian youth // Bulletin of the South Russian State Technical University. Series: Socio-economic Sciences. 2021; 14(5): 27-34. (In Russ.). http://dx.doi.org/10.17213/2075-20672021-5-27-34.

Введение. Категория доверия прочно утвердилась в социально-гуманитарной мысли, означая, что в условиях социальной неопределенности, неоднозначных тенденций в развитии социально-нормативной системы общества особое место имеет доверие как субъективный аспект общественных отношений, как система ожиданий в отношении социальных субъектов, имеющая если не предопределенный, то прогнозируемый характер. Действительно, в современном обществе, как показывает видный социолог П. Штомпка, культура доверия является социальным капиталом, символическое измерение которого конвертируется в экономический, властный, культурный капиталы. Говоря об этом, следует иметь в виду, что доверие/ недоверие выступает важным фактором снижения или повышения трансакционных издержек в экономике, правовых и политических рисков, влияет на уровень социальной консолидации и связь между публичным дискурсом и межличностным общением. 
Правовое сознание российской молодежи, которое можно определить как интегрированность идей, норм, принципов, представлений о сущности права и правовых механизмах общества, выявляется не только в феномене законопослушности, допустимости или недопустимости иллегальных (неправовых) практик, но и в институциональном доверии к правовым институтам и межличностном доверии к социальным субъектам как носителям правового поведения. Независимо от оценки тенденции неоднородности правового сознания молодежи, надо отметить, что в сфере правового сознания имеют место определенные правовые парадоксы и коллизии, что правовое сознание российской молодежи соединяет принятие права как атрибута современной личности и вместе с тем под влиянием социальных рисков характеризуется средней степенью толерантности к неправовым феноменам.

Основная часть. В российском обществе доверие имеет специфический характер и основывается, прежде всего, на доверии к государству и институту Президента. Об этом свидетельствуют данные социологических исследований, в которых институт Президента «венчает» иерархию социальных и властных институтов [1]. Очевидно, что доверие российской молодежи является производным от показателей социальной адаптации, множественности социальных ролей, типов социального поведения молодого поколения, но самое важное состоит в том, что его можно характеризовать как «ставку на будущее». Это требует уточнения и конкретизации, так как если исходить из социального опыта, молодежь в меньшей степени, чем старшее поколение, занимает позицию безусловного доверия, того, что именуют этатистским или государственническим комплексом.

Однако есть необходимость осмысливать доверие в правовом сознании российской молодежи как явление, связанное не с опекунскими ожиданиями со стороны государства и общества, а в большей степени как совокупность факторов, движимых стремлением молодежи занимать самостоятельные позиции, смотреть с уверенностью в будущее и через правовые институты расширять коридор жизненных возможностей. Ожидания, связанные с правовыми институтами, в правовом сознании российской молодежи содержат не меньшие, а более высокие требования к эффективности правовой регуляции по сравнению со старшими поколениями. Обосновывая данную мысль, есть смысл опираться на то, что российская молодежь в виде трех постсоветских поколений не знает и не в состоянии использовать предшествующий социальный опыт взаимоотношений личности, общества и государства, что обоснованность доверия или недоверия в правовом сознании российской молодежи является и структурной, и ситуативной. Структурной - как признание молодежью роли правовой регуляции в реализации жизненных планов, ситуативной - в прагматике использования правовых механизмов. Причины, по которым молодежь склонна к правовым практикам или, наоборот, их отвергает и ограничивает, определяется готовностью достижения жизненных целей через отклонение или принятие права в качестве способа социального действия.

Здесь важным моментом является то, что мы можем охарактеризовать как импульсы доверия, то есть доверие как система ожиданий, связанных с функционированием правовых институтов, постоянно изменяется, и объясняется это тем, в какой степени право актуализировано в жизни общества, влияет на межличностный и межгрупповой уровни. Поясняя эту мысль, можно говорить о том, что доверие становится механизмом правовой регуляции и саморегуляции молодежи при реализации трех условий. Первое связано с легитимацией правовых институтов, с признанием их приоритетности в регулировании общественных отношений, а не только социальных и межличностных конфликтов. Второе - с тем, что в нынешних условиях, когда правовые институты под влиянием объективных и субъективных факторов могут быть нонфункциональны, выполнять возложенные на них функции только частично или выборочно, доверие является фактором стабильной самооценки молодежи, демонстрации того, что российская молодежь оценивает современное общество с позиции приоритетности или периферийности правовых институтов.

К такому выводу пришли российские исследователи М.К. Горшков и Ф.Э. Шереги, когда на уровне масштабного долгосроч- 
ного мониторинга молодежи сделали вывод о том, что формирование правового сознания российской молодежи связано не столько с провозглашением идеи построения демократического правового государства, сколько с тем, чтобы молодежь ощущала, воспринимала и оценивала действующую систему права и реформирования правовых институтов [2]. 51,5\% респондентов придерживались позиции, что Россия «не совсем является» правовым государством [2]. Такой внешне уклончивый ответ не является попыткой уйти от однозначных суждений и оценок. Можно предположить, что на заявленную позицию влияет фактор доверия к правовым институтам, так как при определенном скепсисе и негативизме восприятия действительности право является «желательным», и с ним связывается комплекс представлений о законности, независимости судов, соблюдении прав и свобод граждан.

Следует подчеркнуть, что доверие является для молодежи нормативным, что характеризует идеальность представлений о том, как должны функционировать правовые институты в российском обществе. Инструментальные значения доверия имеют более низкий уровень, так как молодежь говорит о полуправовом характере российского общества, о том, что право вошло в общественные отношения, воспринимается необходимым, но не является должным. Как пишут Ю.А. Зубок и В.И. Чупров, в условиях социальной неопределенности вступления молодежи во взрослую жизнь доверие в правовом сознании российской молодежи ограничивает экстремальные, рискогенные проявления в ее социальном поведении, то есть по показателям доверия можно говорить о том, что молодежь не демонстрирует безусловное доверие, которое является результатом, скорее, смешения права и традиционности, а видит в праве и правовых институтах средства рационализации общественных отношений, повышения их прогнозируемости и планируемости [9].

В данном случае авторы говорят об экстремальных настроениях в различных сферах жизнедеятельности молодежи, но, по существу, рассматривают доверие как интегративный показатель дистанцированности или эмпатии молодежи к базисным социальным институтам российского общества. При том что, как отмечают авторы, у молодежи доминирует нигилизм по отношению к институтам власти и общественным организациям, не стоит торопиться с выводом о том, что российская молодежь индифферентна или нигилистически настроена по отношению к правовым институтам.

В правовом сознании российской молодежи правовой нигилизм не воспринимается заслуживающим высокой оценки. Другое дело, что доверие ориентировано на эффективность правовых институтов так же, как и недоверие основывается на сбоях, дефицитах правовых регуляторов и решении жизненных проблем неправовыми способами. Доверие, таким образом, имеет нормативную ориентированность в представлениях о миссии правовых институтов в обществе, инструментальную в оценке конкретных результатов функционирования и генерализирующую - в осознании значимости доверия как обязательного правила поведения в обществе.

Исходя из этого, можно говорить о том, что доверие в правовом сознании молодежи дифференцировано. Здесь приоритетным можно считать нормативность, ориентированность молодежи на функциональность правовых институтов, на реализацию их ожиданий, связанных с правовыми нормами. Доверие имеет шансы быть нормативным в молодежной среде, если правовое сознание основывается на конституирующей идее права, на том, что правовые институты являются условием позиционного доверия молодежи к представителям правовых институтов и уверенности в том, что функционирование правовых институтов определяется профессионализмом, соблюдением обязательных формальных норм и правовые институты действуют в интересах молодежи как формальные «безличностные» регуляторы. Это интересный момент, характеризующий отличие молодежи от среднего и старшего поколений, воспринимающих право лишенным «неформальности», свободным от подозрений в непотизме и возможности не предпринимать действия в целях предотвращения рискогенных ситуаций на основании того, что личность подвергается опасности или спонтанным непредсказуемым воздействиям. 
Нормативная ориентированность доверия российской молодежи укладывается в реальность множественности социальных ролей, в которые вовлечена молодежь, требующих применения правовых норм, не являвшихся актуальными в предшествующий период, в частности, в сферах бизнеса, наследования, кредитования, страхования. Таким образом, российская молодежь вовлечена в правовые практики, что по сравнению со средним и старшим поколением является необходимостью, связана с правовыми знаниями и, что не менее важно, - со способностью актуализации правовой компетентности на институциональном уровне.

Инструментальная ориентированность молодежи на доверие к праву основывается в рамках баланса доверия/недоверия, то есть представители молодого поколения, работающие в сферах высоких технологий, сервиca, логистики, менеджмента, воспринимают правовые механизмы в качестве «рабочих условий». Для них важными являются эффективность института права, минимизация рисков правового произвола и в конечном счете конвертация правового регулирования в ожидаемые результаты. Иначе говоря, российская молодежь основывается на доверии вне определения права в его «высоком значении», то есть не ставит вопрос об идеальности права как конечной цели развития общества.

Мы уже отмечали, что правовой негативизм не является формой самоутверждения молодежи [9]. С другой стороны, нельзя с большой степенью уверенности говорить о том, что в молодежной среде доминирующей является инструментальность права как безоговорочная основа доверия к праву. Дело в том, что существует риск отклонения правовых норм не в контексте представления о должном и реальном праве, а связанный с возможностями реализации жизненных планов. Как показывают результаты социологических исследований, умеренное доверие к правовым институтам определяется запросом на правовые регуляторы. Здесь следует учитывать, что для российской молодежи права и свободы имеют инструментальное значение и могут быть квалифицированы как обоснование действующих стратегий молодежи.

Вместе с тем, руководствуясь собственными интересами в системе правовых отно- шений, респонденты исходят из желаемого статуса, из того, что согласуется с их представлениями о праве. Таким образом, доверие становится транзитивным, определяемым реальными показателями эффективности правовых институтов. В этом убеждаешься, когда заходит речь о разности потенциала доверия по отношению к конкретным правовым институтам. Если брать реальные показатели доверия, можно отметить, что более высокой степенью доверия обладают правоохранительные структуры по сравнению с судебной системой [1]. На наш взгляд, это является следствием того, что за правоохранительными структурами признается реальность права, в то время как судебная система рассматривается как отложенное право, не имеющее гарантированных результатов.

Действительно, правоохранительные структуры воспринимаются в контексте обыденного сознания молодежи, ассоциируются с авторитетом государства, судебная система является системным институтом, общение с которым требует от личности определенного уровня правового сознания, содержащего представления о принятии судебных решений. В пользу такого вывода говорит то, что судебная система, если принимать во внимание мнение молодежи о полуправовом характере государства, квалифицируется как признак правового государства и, следовательно, не относится к конкретным ожиданиям молодежи. Сравнительно низкий уровень доверия к судебной системе в молодежной среде определяется и тем, что для молодых россиян «правильность» судебных решений воспринимается как следствие ресурсных различений участников процесса, что в молодежной среде не утвердилась мысль о правовом равенстве.

На первый взгляд, инструментальная ориентированность доверия противоречит нормативной модели, но в реальности правового сознания российской молодежи нормативность обретает конкретность в инструментальности, полезности правовых институтов. И здесь можно фиксировать сложность перехода от инструментальности доверия к системному уровню, так как молодежь полагает полуправовой характер российского государства и в зависимости от оценки эффективности правовых институтов воспринимает нонфункциональность или как следс- 
твие издержек правового реформирования и становления нового правового порядка, или как несвободу от неправового наследия, а также воспроизводства неправовых рецидивов российского общества.

В этом смысле системное доверие к праву не вошло укорененным образом в правовое сознание российской молодежи. Во многом системное доверие представляется связанным с фундаментальной ценностью права в обществе, но «искажающий» нюанс состоит в том, что правовое сознание российской молодежи не определяет право как культурную модель общественной жизни. В правовом сознании отражается не только социальное положение индивидов и групп, но и готовность к принятию системного доверия [8]. Так как системное доверие к праву предполагает правовое равенство, оно есть результат компромисса реальных интересов и требований различных социальных групп и слоев, и молодежь в этом процессе не является исключением.

Заключение. Неоднородность молодежной среды, ее социальные и культурные различия делают возможной перспективу системного доверия к праву как осознанию экзистенциальности и безальтернативности права для развития общества, государства и личности в контексте роста побудительных стимулов к принятию права в качестве базового условия доверия в обществе. Здесь можно сослаться на исследование американского теоретика А. Селигмена, который отмечал, что в современном обществе право с необходимостью воспринимается как господство закона, лимитирующего границы недоверия между людьми и обязывающего к ответственности в случае нереализации взаимных ожиданий [7]. Так как на межличностном уровне проявляется эгоистичность частных интересов, а моральные ценности не могут гарантировать доверие, речь идет о том, что доверие к праву является генерализированным обменом, то есть личность может сомневаться во многом, но не подвергать скепсису правовые нормы в силу их универсальной договоренности.

Это аналитическое рассуждение проясняет ситуацию, в которой российская молодежь не достигла уровня системного доверия к праву, но не отделяет правовые институты от государства в целом, учитывая тот факт, что общественные ассоциации, занятые правовой деятельностью, не авторитетны в молодежной среде. Таким образом, системное доверие к праву актуализирует высокую степень интолерантности молодежи к неправовым явлениям. Самое главное - следует обратить внимание на формирование в правовом сознании российской молодежи установки на решение конфликтов правовыми способами.

Поэтому категория доверия в правовом сознании российской молодежи может считаться социально зафиксированной, характеризующей снижение уровня правового нигилизма, по сравнению с предшествующим десятилетием, вместе с тем доверие, где доминируют нормативный и инструментальный смысл, не блокирует риски неправовых практик молодежи. Неправовые практики в молодежной среде связаны с адаптивными стратегиями, особенно в условиях социально-экономического кризиса. И так как системное доверие не характеризует правовое сознание молодежи в ее социально-ориентационном и социально-регулятивном аспектах, есть смысл говорить о том, что для формирования позитивного отношения к праву в молодежной среде предстоит пройти дистанцию исчезновения отчуждения между правовыми институтами и социальными практиками молодежи, достичь консенсуса в российском обществе на основе принятия реститутивной формулы права.

\section{Список источников}

1. Горшков М.К. и др. Российское общество и вызовы времени. Кн. 2. М.: Издательство Весь Мир, 2015. 432 с.

2. Горшков М.К., Шереги Ф.Э. Молодежь России. М.: ЦСПиМ, 2010. 592 с.

3. Дискин И. А. Россия, которая возможна. М.: «Юрист», 2011. 175 с.

4. Зубок Ю., Чупров В. Социальная регуляция в условиях неопределенности: теоретические и прикладные проблемы в исследовании молодежи. М.: Academia, 2008. 266 с.

5. Куда идет Россия? Формальные институты и реальные практики / Под общ. ред. Т.И. Заславской. М.: МВШСЭН, 2002. 292 с. 
6. Лукин В.Н., Мусиенко Т.В. Модель культуры доверия П. Штомпка: профили рисков // Журнальный клуб Интелрос «Credo New». 2008. №2. C. 25.

7. Селигмен А. Проблема доверия: монография. М.: Идея-Пресс, 2002. 256 с.

8. Социология молодежи: учебник для академического бакалавриата / под ред. Р.В. Ленькова. М.: Издательство Юрайт, 2008. 416 с.

9. Чупров В.И., Зубок Ю. А., Уильямс К. Молодежь в обществе риска. М.: Наука, 2001. 229 c.

\section{References}

1. Gorshkov M.K. et al. Rossijskoe obshhestvo i vyzovy vremeni. Kn. 2 [Russian society and the challenges of the time. Book 2]. Moscow: Izdatel'stvo Ves' Mir, 2015. 432 p. (In Russ.).

2. Gorshkov M.K., Sheregi F. Je. Molodezh' Rossii [Youth of Russia]. Moscow: CSPiM, 2010. 592 p. (In Russ.).

3. Diskin I.A. Rossija, kotoraja vozmozhna [Russia, which is possible]. Moscow: «Jurist», 2011. 175 p. (In Russ.).

4. Zubok Ju., Chuprov V. Social'naja reguljacija $\mathrm{v}$ uslovijah neopredelennosti: teoreticheskie i prikladnye problemy $\mathrm{v}$ issledovanii molodezhi [Social regulation in conditions of uncertainty: theoretical and applied problems in the study of youth]. Moscow: Academia, 2008. 266 p. (In Russ.).

5. Kuda idet Rossija? Formal'nye instituty i real'nye praktiki [Where is Russia going? Formal institutions and real practices]. Pod obshh. red. T.I. Zaslavskoj [In T. I. Zaslavskaya (eds.)]. Moscow: MVShSJeN, 2002. 292 p. (In Russ.).

6. Lukin V.N., Musienko T.V. Model' kul'tury doverija P. Shtompka: profili riskov [Model of trust culture P. Shtompka: risk profiles]. Zhurnal'nyj klub Intelros "Credo New» [Intelros Magazine club «Credo New»]. 2008; 2: 25. (In Russ.).

7. Seligmen A. Problema doverija: monografija [The problem of trust: monograph]. Moscow: Ideja-Press, 2002. 256 p. (In Russ.).

8. Sociologija molodezhi: uchebnik dlja akademicheskogo bakalavriata [Sociology of Youth: Textbook for academic Bachelor's degree]. Pod red. R. V. Len'kova [In R. V. Lenkov (eds.)]. Moscow: Izdatel'stvo Jurajt, 2008. 416 p. (In Russ.).

9. Chuprov V.I., Zubok Ju. A., Uil'jams K. Molodezh' $\mathrm{v}$ obshhestve riska [Youth in a risk society]. Moscow: Nauka, 2001. 229 p. (In Russ.).

Статья поступила в редакиию 02.09.2021; одобрена после рещензирования 12.09.2021; принята к публикаиии 25.09.2021.

The article was submitted on 02.09.2021; approved after reviewing on 12.09.2021; accepted for publication on 25.09.2021.

\section{ИНФОРМАЦИЯ ОБ АВТОРАХ}

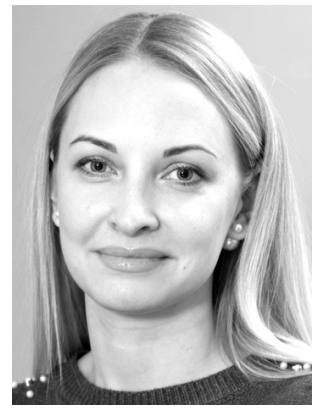

Искендерова Яна Юрьевна - кандидат социологических наук, доцент кафедры «Юриспруденция», Южно-Российский государственный политехнический университет (НПИ) имени М. И. Платова.

Россия, Новочеркасск, ул. Просвещения, 132

Yana Yu. Iskenderova - Candidate of Sociological Sciences, Associate Professor of the Department of Jurisprudence, Platov South Russian State Polytechnic University (NPI).

132 Prosveshcheniya st., Novocherkassk, Russia 


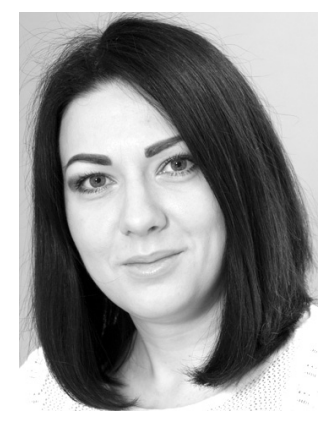

Левченко Ирина Андреевна - кандидат философских наук, доцент кафедры «Юриспруденция», Южно-Российский государственный политехнический университет (НПИ) имени М.И. Платова.

Россия, Новочеркасск, ул. Просвещения, 132

Irina A. Levchenko - Candidate of Philosophical Sciences, Associate Professor of the Department of Jurisprudence, Platov South Russian State Polytechnic University (NPI).

132 Prosveshcheniya st., Novocherkassk, Russia

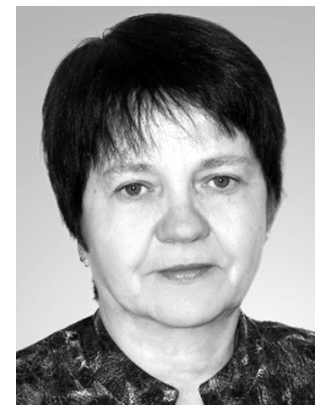

Сережникова Татьяна Леонидовна - старший преподаватель кафедры «Юриспруденция», Южно-Российский государственный политехнический университет (НПИ) имени М.И. Платова.

Россия, Новочеркасск, ул. Просвещения, 132

Tatyana L. Serezhnikova - Senior Lecturer, Department of Jurisprudence, Platov South Russian State Polytechnic University (NPI).

132 Prosveshcheniya st., Novocherkassk, Russia

Вклад авторов:

Искендерова Я. Ю. - разработка дизайна исследования; существенный вклад в концепцию и дизайн исследования.

Левченко И. А. - получение данных, их анализ и интерпретация; написание первой версии статьи.

Сережникова Т.Л. - критический пересмотр статьи на предмет важнного интеллектуального содержания; одобрение окончательной версии статьи перед ее подачей для публикации.

Contribution of the authors:

Iskenderova Y. Yu. — development of research design; significant contribution to the concept and design of research.

Levchenko I. A. - data acquisition, analysis and interpretation; writing the first version of the article.

Serezhnikova T. L. - critical revision of the article for important intellectual content; approval of the final version of the article before submitting it for publication. 